\title{
AÇÕES PREVENTIVAS CONTRA O USO DE ÁLCOOL E DROGAS: RELATO DE EXPERIÊNCIA
}

\author{
Rosália Arêdes T. Xavier', Lorena O. Silva', Vanessa Meira Maia ${ }^{1}$ \\ Rita Narriman Silva de Oliveira Boery², Eduardo Nagib Boery ${ }^{2}$
}

\section{RESUMO}

Este estudo se trata de um relato de experiência de alunos bolsistas de um projeto de extensão do Departamento de Saúde da Universidade Estadual do Sudoeste da Bahia (UESB), que executa ações de prevenção contra o uso de álcool e drogas. O trabalho justifica-se pelo aumento do número de usuários de drogas, o que repercute negativamente no contexto social do município de Jequié, na Bahia. As ações são desenvolvidas por meio de palestras, reuniões, oficinas com grupos escolares e religiosos, feiras de saúde e grupos de comunidades, a fim de diminuir as estatísticas sobre os usuários de drogas nessa cidade. Essas atividades mostram a importância de prevenir o primeiro contato com substâncias tóxicas, no intuito de favorecer a qualidade de vida e a saúde mental da população, com métodos mais saudáveis. Com essas atividades de extensão, foi possível perceber a importância do esclarecimento sobre as consequências negativas do uso de álcool e substâncias ilícitas no organismo do indivíduo e no contexto intrafamiliar e social.

Palavras-chave: Drogas. Prevenção. Qualidade de Vida.

\footnotetext{
${ }_{1}$ Acadêmicas de Enfermagem da Universidade Estadual do Sudoeste da Bahia (UESB), pertencentes ao Grupo de Pesquisa Saúde e Qualidade de Vida. E-mails: rosaliaaredes@hotmail. com; loreonofre@hotmail.com; nessitamaia@hotmail.com.

${ }^{2}$ Enfermeiros e doutores em Enfermagem pela Universidade Federal de São Paulo (UNIFESP). Docentes do Programa de Pós-Graduação em Enfermagem e Saúde em nível de Mestrado pela UESB. E-mails: rboery@gmail.com; eboery@ig.com.
}

\begin{tabular}{l|l|l|l|l}
\hline Revista Extensão \& Cidadania & Vitória da Conquista & v. 1, n. 1 & p. 53- 63 & jan./jun. 2013 \\
\hline
\end{tabular}




\title{
Preventive action on the use of alcohol and drugs: report of experience
}

\begin{abstract}
This study is an experience report of scholarship students of an extension project of the Department of Health, State University of Southwest Bahia (UESB), which performs preventive measures against the use of alcohol and drugs. The work is justified by the increased number of drug users, which has negative repercussions in the social context of Jequié, Bahia. Actions are developed through lectures, meetings, workshops with school groups and religious, health fairs and community groups in order to reduce the statistics on drug users in this city. These activities show the importance of preventing the first contact with toxic substances in order to promote quality of life and mental health of the population, with healthier methods. With these extension activities, it was possible to realize the importance of clarification about the negative consequences of alcohol use and illicit substances in the body of the individual and the social context and intrafamilial.
\end{abstract}

Keywords: Drugs. Prevention. Quality of Life.

\section{Introdução}

Esse estudo é resultado do trabalho desenvolvido pelos bolsistas do Projeto de Extensão "O despertar contra o uso das drogas: a importância do esclarecimento visando à prevenção e reabilitação", do Departamento de Saúde da Universidade Estadual do Sudoeste da Bahia, campus de Jequié-BA. Esse relato de experiência discorre acerca do processo de prevenção contra o uso de drogas lícitas/ilícitas e pretende encontrar subsídios que possam ajudar a comunidade, de maneira geral, a adotar as estratégias de interdisciplinaridade, o que contribui para a diminuição da proporção de usuários e melhoria da qualidade de vida de toda a população, mediante informação, promoção e educação em saúde.

O avanço do consumo das drogas ilícitas e do alcoolismo é um fenômeno que vem preocupando profissionais, famílias e instituições civis, militares e religiosas em virtude da proporção que vem tomando na sociedade. São muitos os esforços em reverter ou minorar 
esse crescimento, mas ainda existe uma lacuna no que se refere ao oferecimento de mecanismos eficazes para a prevenção, controle e reabilitação dessa parcela da população.

Esse projeto de extensão aplicou a sua metodologia por meio de palestras, oficinas e reuniões que enfocaram a importância da discussão sobre a problemática das drogas na construção de uma sociedade mais comprometida com a qualidade de vida e com a saúde mental e orgânica de seus componentes. Com o intuito de realizar educação em saúde e informar a população, principalmente os jovens, sobre as substâncias psicoativas, as ações do projeto incluem prevenir o primeiro contato, e conscientizá-los de como um indivíduo se torna viciado, além dos efeitos das substâncias e os prejuízos para a vida social e pessoal do usuário. Busca-se, ao mesmo tempo, ampliar o nível de conhecimento dos participantes e constituir a opinião dos mesmos sobre a relevância do assunto para os diversos ramos sociais, como forma de integração com a comunidade e suas expectativas, reafirmando as transformações efetivas no processo pedagógico e a interação entre a universidade e a comunidade.

Durante a execução das atividades de extensão foi realizada uma discussão com os participantes a fim de adquirir informações acerca de seus conhecimentos sobre drogas e avaliar o desempenho das palestrantes na explanação e transmissão do conteúdo. A abordagem incluiu as drogas mais comuns: tabaco, álcool, maconha, cocaína, crack, LSD, lança-perfume, esteroides anabolizantes e o tipo recentemente descoberto, a oxi; e as composições dessas drogas e os efeitos maléficos para o funcionamento normal do organismo, com a finalidade de esclarecer, conscientizar e sensibilizar o público sobre os prejuízos para a saúde, que estão além da vida pessoal do usuário.

Considerar que a proporção do uso de drogas em muitas comunidades brasileiras tem se tornado cada vez maior no cotidiano dos adolescentes é um fato lamentável que confirma a falta de informação da comunidade e da participação social na prevenção do aumento do número de usuários de drogas lícitas e/ou ilícitas. 
Dentro dessa vertente, esse estudo tem como cenário o município de Jequié, na Bahia, o qual vem sendo, de forma preocupante, alvo constante do aumento do número de pessoas usuárias de drogas, de modo que os reflexos dessa problemática podem ser percebidos em sua imagem social, em forma de violência, criminalidade, marginalização e insegurança.

Transformar essa realidade tem se tornado um grande desafio para a comunidade acadêmica na realização das atividades práticas de ensino-pesquisa-extensão, no enfoque de mecanismos de prevenção, controle, informação e exposição de conhecimentos relacionados aos efeitos maléficos - pessoais e sociais - que o uso prolongado de entorpecentes pode acarretar na vida de um indivíduo e, também, na prevenção do primeiro contato, quase sempre decisivo para o vício.

\section{Desenvolvimento}

Desde o nascimento, todos os seres vivos, em especial os humanos, passam por várias transformações físicas, psíquicas, fisiológicas e emocionais, influenciadas pelos vários ambientes em que são inseridos desde os primeiros dias de vida e ao longo de toda a trajetória do seu desenvolvimento.

Embora muitas pessoas não acreditem, alguns tipos de comportamento de indivíduos, ao chegarem à adolescência, podem estar relacionados aos reflexos das imposições ambientais vividas na infância. $\mathrm{O}$ contexto familiar, o relacionamento interpessoal desde a infância, o convívio social, o processo de educação e a preocupação, tanto da família quanto dos educadores, em relação à conscientização sobre o uso de drogas, podem desencadear atitudes de rebeldia e revolta, culminando na escolha do primeiro contato com as drogas (SANCHEZ et al., 2005).

O uso de drogas na adolescência é uma questão que preocupa cada vez mais os pesquisadores e profissionais da saúde e da educação. As pesquisas epidemiológicas mostram que o uso e abuso de drogas aumenta em ritmo acelerado e que é na adolescência, em geral, que se inicia o consumo. Ao mesmo tempo observa-se que o tema das drogas é frequente na mídia (RIBEIRO et al., 1998). 
Segundo Lima et al. (2008), o primeiro movimento realizado em direção às drogas se dá quase sempre nessa fase, por ser um período especialmente crítico e cheio se situações de decisão e escolha. Entre os 12 e os 20 anos, o indivíduo sente-se exigido pelos pais e pela sociedade, que lhe impõem definição e determinação de um rumo para sua vida.

Partindo desse raciocínio inicial, uma das questões com a qual nos defrontamos quando o assunto é dependência química é: o que leva os indivíduos a usarem drogas? Muitas vezes, este é um questionamento de difícil resposta, ao pensar que não se pode generalizar uma explicação a respeito de todos os indivíduos usuários de drogas. Em se tratando de consumo, parece que sempre existem ideias prontas impostas e explicações construídas no sentido de ocultar suas reais causas, mas a principal preocupação é compreender a origem dos processos que fazem com que muitos jovens recorram à alternativa do consumo de entorpecentes, seja como ato de rebeldia seja como ato de refúgio, em relação às mudanças no contexto físico e emocional muito característico da adolescência.

Fazem parte da natureza dos jovens a imprudência e o desejo de experimentar novas sensações, mas é da natureza humana a busca do conforto, do prazer, e estes sempre foram poderosos estímulos para o uso de substâncias que poderiam proporcionar tais sentimentos (NERI FILHO, 1995). E quando falamos de jovens (o público-alvo deste estudo) é notável que muitos pais tratem esse assunto como tabu, ou proibindo ou amedrontando, deixando que o conhecimento seja adquirido pelos telejornais ou internet. Essa conduta pode prejudicar a formação de um vínculo de confiança que deve ser estabelecido desde cedo, como forma de impedir e evitar que o consumo de drogas ilícitas ou bebida alcoólica penetre na vida do indivíduo e altere seu contexto familiar e social (COURA, 2009).

A dependência química pode ser provocada pela desestruturação familiar e social e é capaz de causar significativa desagregação de ambas, repercutindo no isolamento pelo vício, no comprometimento social, e, além disso, na contribuição para um aumento diretamente 
proporcional entre os custos com o tratamento a longo prazo e sequelas para o organismo, o que pode até custar a vida do próprio paciente (BOERY et al., 2007).

O trabalho desenvolvido pelo projeto de extensão: “O despertar contra o uso das drogas: a importância do esclarecimento visando à prevenção e reabilitação" almeja atingir as escolas, os clubes, as igrejas e grupos sociais, começando pelo público jovem, com o objetivo de informar e esclarecer as dúvidas quanto aos tipos de drogas mais consumidas e conhecidas pelas pessoas. Por meio de questionamentos levantados pela palestrante, foi possível levar os ouvintes a compreenderem o que pode influenciar uma pessoa a iniciar o consumo de drogas, sejam elas ilícitas ou não. Além de refletir sobre a composição química das drogas e os efeitos das substâncias no organismo, a curto e a longo prazo, discutiu-se, também, sobre os impactos do vício na vida do indivíduo e a contribuição para o aumento da criminalidade e da violência na sociedade.

Para além da violência, o abuso de álcool e de drogas ilícitas causa uma série de agravos, como agressões, depressão, distúrbios de conduta, comportamento sexual de risco e acidentes de trânsito. É um debate que segue concentrado nas dimensões da Segurança Pública e da Justiça. Para Francisco Inácio Pinkusfeld Bastos, pesquisador da Fundação Oswaldo Cruz, que se dedica ao estudo do abuso de drogas e do HIV/AIDS, não existe discussão válida sobre drogas fora do âmbito da saúde, uma vez que o uso dessas substâncias causa impacto diretamente na vida do indivíduo (DOMINGUEZ, 2011).

É importante enfatizar que a decisão de usar substâncias entorpecentes, por vezes, não está limitada apenas a um tipo de droga, ou seja, vários tipos de entorpecentes podem ser adquiridos pelo fácil acesso, muitos desses entorpecentes, já incluídos entre as drogas utilizadas pelos grupos de usuários/viciados, o que resulta em um processo de dependência cada vez mais progressiva e degradante para a própria saúde e para a sua relação intrafamiliar. 
Ao abordar sobre os vários tipos de drogas utilizadas, as palestras buscaram dar ênfase ao álcool e ao tabaco - drogas lícitas mais consumidas - e ao crack, por serem espécies de entorpecentes capazes de repercutir mais negativamente na vida do usuário (WAGNER; ANDRADE, 2008) e o crack está cada vez mais presente como droga causadora de intensa dependência entre os usuários. Tais psicoativos são responsáveis, com muita frequência, pelo surgimento de doenças cardiovasculares, acidentes de trânsito e enorme potencial de morte, respectivamente. Outros tipos de drogas também foram abordados, e seus efeitos discutidos e debatidos com os participantes.

Os problemas associados ao uso abusivo das drogas estão diretamente ligados à saúde pública, uma vez que, possuem maior gravidade quando representam reflexos sociais negativos, como a criminalidade, a violência, a marginalização, a desigualdade social e a insegurança. A fase da adolescência torna-se marcante quando o assunto é o uso de álcool e drogas ilícitas, pois deixam o jovem bastante vulnerável por causa da presença de instabilidades emocionais marcadas pela influência de grupos de amigos, a busca pelo desconhecido, a curiosidade, a fuga das dificuldades e a contradição dos valores estabelecidos pelos familiares (LIMA et al., 2008).

Segundo Sanchez et al. (2005), o próprio contexto familiar, o uso de drogas pelos pais, a desestrutura familiar, os episódios de violência doméstica, podem estar ligados aos fatores típicos da adolescência como os conflitos psicossociais, a necessidade de integração social, a busca da auto-estima e a independência familiar. Essa rede de comportamentos interligados proporciona condições que podem determinar a escolha do uso de uma ou mais drogas, e com o aumento da quantidade das drogas, os efeitos potencializam ainda mais os riscos para dependência e o surgimento de problemas de saúde associados.

A repercussão do uso de drogas vai além da experiência do primeiro contato, as causas da vontade de experimentar são determinantes para que um indivíduo não pare até que o vício aconteça. As relações afetivas são um ponto fundamental nas discussões durante as palestras, além dos relacionamentos familiares, das amizades, e dos 
tipos de comportamentos do próprio indivíduo, tais como: isolamento, hiperatividade, espírito aventureiro - capazes de conduzi-lo a utilização dessas substâncias.

E diante dessa realidade, presente no cotidiano da atividade profissional do enfermeiro, busca-se na formação o conhecimento baseado na ciência e nos processos fisiológicos do ser humano, além do conhecimento do contexto social e familiar desses usuários, em contribuição para o seu retorno à rotina de vida interrompida pelo uso das drogas. Por meio de palestras, oficinas e reuniões, tentou-se ampliar os conhecimentos dos jovens acerca das substâncias psicoativas ilícitas, e como reflexo do trabalho, os profissionais também adquiriram experiência e satisfação por contribuírem com a conscientização sobre os danos causados pelo vício em álcool e drogas.

Como estratégia para a diminuição do número de usuários de drogas na cidade de Jequié, na Bahia, as atividades de extensão pretendem mostrar o quão importante é prevenir o primeiro contato, e incentivar a prática de hábitos que melhorem a qualidade de vida da população em geral, como atividades físicas, oficinas, artesanatos, esportes e atividades religiosas. Além disso, a integração com a comunidade faz com que se estabeleçam vínculos de corresponsabilidade, na valorização do trabalho realizado e no reconhecimento dos profissionais de saúde, como forma de evitar que o número de usuários e viciados continue crescendo estatisticamente.

O conhecimento adquirido durante as ações de prevenção foram capazes de apontar a eficiência de um compromisso com a mudança da realidade social. Ao lidar com as diferentes faixas etárias pode-se perceber que a preocupação existe, mas o conhecimento dos problemas ocasionados pelas drogas é ainda ignorado. Por isso, informar a população é uma estratégia importante a fim de iniciar o ciclo de mobilização como fator determinante para a reconstrução familiar e social, da mesma forma que o processo de conscientização da prevenção ao primeiro contato pode ser capaz de refletir na diminuição da violência, da criminalidade e da desigualdade social. 


\section{Metodologia}

Esse relato de experiência é o resultado do trabalho realizado por intermédio do Projeto de Extensão "O despertar contra o uso das drogas: a importância do esclarecimento visando à prevenção e reabilitação", do Departamento de Saúde da Universidade Estadual do Sudoeste da Bahia, campus de Jequié - BA. Inicialmente, foi realizado um contato com coordenadores de escolas, de grupos religiosos e de grupos comunitários e, então, foi feito um agendamento com esses líderes a fim de que o máximo de pessoas pudesse participar das atividades. As informações foram expostas por um kit multimídia, com projeção de imagens em PowerPoint. Os participantes receberam um folheto contendo as principais informações e pontos de discussão da palestra e, ao mesmo tempo, foram submetidos a um pequeno questionário em que eles mesmos puderam avaliar o desempenho dos palestrantes e a qualidade das informações expostas. Como objetivos estavam incluídos: a análise da percepção dos jovens suscetíveis e/ou envolvidos com uso de drogas, informando sobre os mecanismos de prevenção e controle no uso; a ampliação dos conhecimentos da problemática para gerar serviço multiprofissional de apoio aos sujeitos susceptíveis e/ou envolvidos; e a análise da percepção dos jovens do município de Jequié no que se refere ao uso lícito e/ou ilícito de drogas e álcool.

\section{Conclusão}

Esse estudo proporcionou um aprendizado significativo para os executores das atividades do projeto de extensão, visto que, ao perceberem que a população adolescente se preocupa em conhecer e adquirir informações acerca desse assunto pôde-se compreender que, muitas vezes, a repercussão do uso das drogas se dá pela falta de comunicação e diálogo no convívio intrafamiliar. A escola e os profissionais de saúde, em quaisquer ramos multidisciplinares, devem atuar de forma eficaz no combate ao uso de drogas, esclarecendo e aumentando a preocupação do público a respeito dessa realidade, 
que pode ser modificada, e os jovens são bons instrumentos para a transformação dessa problemática no município de Jequié, assim como em todo o Brasil.

O contexto do uso de drogas envolve muitos problemas sociais, e os profissionais devem assumir o compromisso com a ética profissional e com a cidadania. O esclarecimento acerca dos efeitos causados pelo vício é uma estratégia que deve ser efetivamente difundida como forma de provar e estabelecer a certeza de que recorrer ao uso de drogas será apenas mais uma maneira de agravar os problemas em vários contextos e que a realidade de um usuário impõe sua própria condição de risco de solidão e morte, ao mesmo tempo em que diminui as perspectivas e a esperança de uma realidade mais ativa e participativa para o jovem, nos problemas sociais enfrentados.

\section{Referências}

BOERY, Eduardo Nagib et al. Evitando o primeiro contato e/ ou livrando-se da dependência das drogas. Jequié-BA: UESB, 2007.

COURA, Kalleo. Droga: música, sexo e loucura. VEJA, Rio de Janeiro: Editora Abril, edição 2135, n. 42, p. 134-139, out. 2009.

DOMINGUEZ, Bruno. O desafio de uma política equilibrada para as drogas. RADIS COMUNICAÇÃO EM SAÚDE, Rio de Janeiro: Escola Nacional de Saúde Pública Sérgio Arouca e Fundação Oswaldo Cruz, n. 101, p. 14, jan. 2011.

LIMA, Iara Santos et al. História oral de vida de adolescentes dependentes químicos, internados no setor de psiquiatria do hospital regional de Mato Grosso do Sul para tratamento de desintoxicação. SMAD, Rev. Eletrônica Saúde Mental Álcool Drog. (Ed. port.), v. 4, n. 1, p. 00-00. ISSN 1806-69762008.

NERI FILHO, A. Preconceitos e conceitos sobre drogas. In: Drogas, AIDS e Sociedade. Brasília: CDIC, 1995. 
RIBEIRO, Tatiana Weiss;PERGHER, Nicolau Kuckartz;TOROSSIAN, Sandra Djambolakdjian. Drogas e adolescência: uma análise da ideologia presente na mídia escrita destinada ao grande público. Psicologia: Reflexão e Crítica [online], v. 11, n. 3, p. 421-430, 1998.

SANCHEZ, Zila van der Meer; OLIVEIRA, Lúcio Garcia de; NAPPO, Solange Aparecida. Razões para o não-uso de drogas ilícitas entre jovens em situação de risco. Revista Saúde Pública, São Paulo, v. 39, n. 4, p. 599-605, 2005.

WAGNER, Gabriela Arantes; ANDRADE, Arthur Guerra de. Uso de álcool, tabaco e outras drogas entre estudantes universitários brasileiros. Revista de Psiquiatria Clínica, São Paulo, v. 35, supl. 1, p. 48-54, 2008. 